\title{
Positron Emission Tomography (PET) Imaging of Prostate Cancer with a Gastrin Releasing Peptide Receptor Antagonist - from Mice to Men
}

\author{
Gesche Wieser ${ }^{1 * \otimes}$, Rosalba Mansi ${ }^{1 *}$, Anca L. Grosu², Wolfgang Schultze-Seemann ${ }^{3}$, Rebecca A.
} Dumont-Walter1,4, Philipp T. Meyer ${ }^{1,5}$, Helmut R. Maecke1,5, Jean Claude Reubi ${ }^{6}$, Wolfgang A. Weber 1,7

1. Department of Nuclear Medicine, University Hospital Freiburg, Germany.

2. Department of Radiation Oncology, University Hospital Freiburg, Germany.

3. Department of Urology, University Hospital Freiburg, Germany.

4. Department of Radiology, David Geffen School of Medicine, UCLA, Los Angeles, CA, USA.

5. German Cancer Consortium (DKTK).

6. Division of Cell Biology and Experimental Cancer Research, Institute of Pathology, University of Berne, Switzerland.

7. Molecular Imaging and Therapy Service, Memorial Sloan Kettering Cancer Center, New York, NY, USA.

* First authors (both authors contributed equally to this work): Gesche Wieser (resident, MD) and Rosalba Mansi (PhD), Hugstetter Straße 55, 79102 Freiburg i. Br., Germany, Phone: +49-761-27039160, Fax:+49-761-27039300, gesche.wieser@uniklinik-freiburg.de or rosal-

ba.mansi@uniklinik-freiburg.de

Corresponding author: Gesche Wieser, Hugstetter Straße 55, 79102 Freiburg i. Br., Germany, Phone: +49-761-27039160, Fax: +49-761-27039300, gesche.wieser@uniklinik-freiburg.de.

(c) Ivyspring International Publisher. This is an open-access article distributed under the terms of the Creative Commons License (http://creativecommons.org/ licenses/by-nc-nd/3.0/). Reproduction is permitted for personal, noncommercial use, provided that the article is in whole, unmodified, and properly cited.

Received: 2013.08.02; Accepted: 2013.11.09; Published: 2014.02.01

\begin{abstract}
Ex vivo studies have shown that the gastrin releasing peptide receptor (GRPr) is overexpressed on almost all primary prostate cancers, making it a promising target for prostate cancer imaging and targeted radiotherapy.

Methods: Biodistribution, dosimetry and tumor uptake of the GRPr antagonist ${ }^{64} \mathrm{Cu}-\mathrm{CB}-\mathrm{TE} 2 \mathrm{~A}-\mathrm{AR} 06$

[( ${ }^{64} \mathrm{Cu}-4$, I I-bis(carboxymethyl)- I,4,8, I I-tetraazabicyclo(6.6.2)hexadecane)-PEG 4 -D-Phe-GIn-TrpAla-Val-Gly-His-Sta-LeuNH ${ }_{2}$ ] were studied by PET/CT in four patients with newly diagnosed prostate cancer (TIc-T2b, Gleason 6-7).

Results: No adverse events were observed after injection of ${ }^{64} \mathrm{Cu}-\mathrm{CB}-\mathrm{TE} 2 \mathrm{~A}-\mathrm{AR} 06$. Three of four tumors were visualized with high contrast [tumor-to-prostate ratio $>4$ at 4 hours (h) post injection (p.i.)], one small tumor (TIc, $<5 \%$ tumor on biopsy specimens) showed moderate contrast (tumor-to-prostate ratio at $4 \mathrm{~h}$ : 1.9). Radioactivity was cleared by the kidneys and only the pancreas demonstrated significant accumulation of radioactivity, which rapidly decreased over time.

Conclusion: ${ }^{64} \mathrm{CU}-\mathrm{CB}-\mathrm{TE} 2 \mathrm{~A}-\mathrm{AR} 06$ shows very favorable characteristics for imaging prostate cancer. Future studies evaluating ${ }^{64} \mathrm{Cu}-\mathrm{CB}-\mathrm{TE} 2 \mathrm{~A}-\mathrm{AR} 06 \mathrm{PET} / \mathrm{CT}$ for prostate cancer detection, staging, active surveillance, and radiation treatment planning are necessary.
\end{abstract}

Key words: Gastrin releasing peptide receptor, bombesin, PET/CT, prostate cancer.

\section{Introduction}

Treatment options for prostate cancer range from watchful waiting to aggressive multimodal therapies. In order to appropriately stratify patients to different treatment options, there is a need for imaging techniques to accurately localize prostate cancer, determine the extent of disease, follow tumors over 
time, and monitor their response to therapy. Routine imaging studies for prostate cancer include transrectal ultrasound, magnetic resonance imaging, x-ray computed tomography and bone scintigraphy (1). Positron emission tomography (PET) with ${ }^{11} \mathrm{C}$ - or ${ }^{18} \mathrm{~F}$-labeled choline has shown encouraging results for detection of recurrent prostate cancer (2), but has a low diagnostic accuracy for detection of primary prostate cancer, since prostatitis and benign prostatic hyperplasia also show increased choline uptake (3).

An attractive target for a more sensitive and specific imaging of prostate cancer is the gastrin releasing peptide receptor (GRPr), a member of the bombesin receptor family. GRPr and its ligand, gastrin releasing peptide (GRP), are physiologically expressed in the central nervous system and the gastrointestinal tract (4). GRPr overexpression has been observed in a variety of malignant tumors (4), but most consistently in prostate cancer. An autoradiographic study found markedly increased binding of radiolabeled bombesin by prostatic intraepithelial neoplasia (PIN) and in all 30 primary prostate cancers studied. In contrast, normal and hyperplastic prostate tissue demonstrate no or very low binding of bombesin (5).

Based on these data, several groups have studied radiolabeled GRPr agonists for imaging and radionuclide therapy of prostate cancer. However, most of these ligands demonstrated high gastrointestinal uptake and limited metabolic stability in vivo. Furthermore, GRPr agonists can cause acute side effects (abdominal cramps, emesis) when administered at higher doses, which are needed for radionuclide therapy (6). These limitations can potentially be overcome by radiolabeled GRPr antagonists. Non-radioactive labeled GRPr antagonists have been developed as anti-cancer agents, since GRP is involved in mitogenic auto- and paracrine signaling loops (4). In clinical trials, these compounds were found to cause minimal side effects (7).

Our group has developed several radiolabeled GRPr antagonists for imaging and radionuclide therapy of prostate cancer. In mice, these tracers showed higher tumor uptake than GRPr agonists. In addition, the antagonists showed rapid clearance from tissues with physiologic expression (gastrointestinal tract and pancreas), while they were retained for more than $24 \mathrm{~h}$ in GRPr expressing prostate tumor xenografts $(8,9)$. Of the studied GRPr antagonists, ${ }^{64} \mathrm{Cu}-\mathrm{CB}-\mathrm{TE} 2 \mathrm{~A}-\mathrm{AR} 06$ [ $\left({ }^{64} \mathrm{Cu}-4,11\right.$-bis(carb oxymethyl)-1,4,8,11-tetraazabicyclo(6.6.2)hexadecane) -PEG 4 -D-Phe-Gln-Trp-Ala-Val-Gly-His-Sta-LeuNH ${ }_{2}$ ] (Figure 1) demonstrated the most favorable characteristics with respect to tumor uptake and tumor-to-organ ratios (8). The CB-TE2A chelator was chosen as it confers the highest stability for the ${ }^{64} \mathrm{Cu}$-complex in vitro and in vivo (10). Compared to ${ }^{68} \mathrm{Ga} /{ }^{64} \mathrm{Cu}-\mathrm{NODAGA}-\mathrm{AR} 06, \quad{ }^{64} \mathrm{Cu}-\mathrm{CB}-\mathrm{TE} 2 \mathrm{~A}-\mathrm{AR} 06$ showed superior pharmacokinetics with a distinctly higher tumor uptake (8). Imaging with ${ }^{64} \mathrm{Cu}$-CB-TE2A-AR06 can be performed over several hours given the relatively long half-life of ${ }^{64} \mathrm{Cu}(12.7$ h), which allows for better clearance of radioactivity from the urinary bladder. Furthermore, ${ }^{64} \mathrm{Cu}$-based radiopharmaceuticals can be produced centrally and shipped to hospitals without the ability to perform GMP compliant radiolabeling using short-lived radioisotopes such as ${ }^{68} \mathrm{Ga}$. Based on these considerations, we selected the ${ }^{64} \mathrm{Cu}-\mathrm{CB}-\mathrm{TE} 2 \mathrm{~A}-\mathrm{AR} 06$ compound for initial clinical studies.

\section{Patients and Methods}

\section{Patients}

Four patients with newly diagnosed, histologically proven (sextant core needle biopsy) prostate cancer without prior therapy underwent PET/CT imaging with ${ }^{64} \mathrm{Cu}-\mathrm{CB}-\mathrm{TE} 2 \mathrm{~A}-\mathrm{AR} 06$. Patient characteristics are summarized in Table 1 . Renal and hepatic function was normal in all patients as assessed by routine blood tests. ${ }^{64} \mathrm{Cu}-\mathrm{CB}-\mathrm{TE} 2 \mathrm{~A}-\mathrm{AR} 06 \mathrm{PET} / \mathrm{CT}$ scanning was approved by the institutional review board and written informed consent was obtained from all patients. Patients were monitored for safety parameters from the time of administration until the end of the final PET/CT session via interview, electrocardiography and measurements of heart rate and blood pressure. In addition, serum electrolytes, liver and pancreatic enzymes, creatinine levels and blood counts were measured before and 1-2 weeks after injection of ${ }^{64} \mathrm{Cu}-\mathrm{CB}-\mathrm{TE} 2 \mathrm{~A}-\mathrm{AR} 06$.

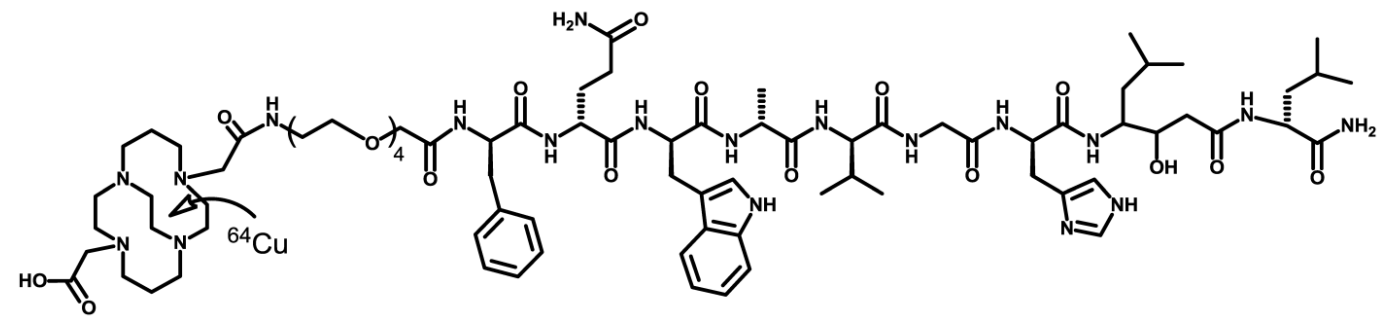

Figure I. Chemical structure of ${ }^{64} \mathrm{Cu}-\mathrm{CB}-\mathrm{TE} 2 \mathrm{~A}-\mathrm{AR} 06$. 
Three patients underwent radiotherapy after the ${ }^{64} \mathrm{Cu}-\mathrm{CB}-\mathrm{TE} 2 \mathrm{~A}-\mathrm{AR} 06$ PET/CT. Patient 4 underwent prostatectomy with local lymph node dissection. In this patient, a sample of the tumor was obtained and processed for in vitro receptor autoradiography with ${ }^{125}{ }^{2}-\mathrm{Tyr}^{4}$-bombesin as described previously (5).

\section{PET/CT imaging}

All imaging studies were performed at the University Hospital Freiburg and approved by the local IRB. Synthesis of the labeling precursor and subsequent ${ }^{64} \mathrm{Cu}$-labeling was carried out as described (8). Briefly, $20 \mu \mathrm{g}$ of the peptide were dissolved in 0.1 $\mathrm{mol} / \mathrm{L}$ ammonium acetate buffer $(\mathrm{pH} 8.0)$ and incubated with ${ }^{64} \mathrm{CuCl}_{2}(220-350 \mathrm{MBq})$ at $95{ }^{\circ} \mathrm{C}$ for 15 minutes (min). Quality controls were performed by analytic reversed-phase high performance liquid chromatography (RP-HPLC, Knauer) with a photo diode array detector (1200 series, Agilent Technologies) and a flow-through RamonaStar (Raytest $\mathrm{GmbH})$ gamma-detector using a Macherey-Nagel Nucleosil 120 C18 column (eluents: A, 0.1\% trifluoroacetic acid in water, and $\mathrm{B}$, acetonitrile; gradient 1 : 0-30 $\mathrm{min}, 95 \%-30 \% \mathrm{~A}$, and flow, $0.750 \mathrm{~mL} / \mathrm{min}$; gradient 2: 0-3 $\mathrm{min}, 95 \%-50 \% \mathrm{~A}$, and flow, $2.5 \mathrm{~mL} / \mathrm{min}$ ). The labeling yield was greater $99 \%$ and radiochemical purity greater $96 \%$. For injection, the radioligand was diluted in $0.9 \% \mathrm{NaCl}$ with $0.1 \%$ bovine serum albumin.

All patients fasted for at least 4 hours before the administration of the radiopharmaceutical and were asked to void before starting the study. Patients underwent a total of three PET scans starting $20 \mathrm{~min}, 4 \mathrm{~h}$ and $20 \mathrm{~h}$ p.i.. For logistical reasons, the first scan was performed with an ECAT EXACT 922 PET scanner (Siemens/CTI, Knoxville, TN) and the second and third scan with a 64-channel GEMINI TF PET/CT (Philips Healthcare, Cleveland, OH). Both scanners were cross-calibrated to ensure the comparability of the quantitative measurements. For attenuation correction of the PET images, one minute transmission scans were performed with three rotating germanium $\left({ }^{68} \mathrm{Ge}\right)$ line sources $(80-100 \mathrm{MBq}$ each). At the time of the second scan, a contrast-enhanced diagnostic CT (120 kVp, 100-400 mAs, dose modulation) was performed, and a low-dose CT (120 kVp, $25 \mathrm{mAs})$ was performed for attenuation correction at the last scan. One patient (patient 4) had a bladder catheter during the time of the PET/CT study because of long-standing urinary tract obstruction.

Venous blood was sampled at 1, 2, 3, 4, 5, 10, 15, $30 \mathrm{~min}, 1,2$, and $4 \mathrm{~h}$ p.i. and the amount of radioactivity per $\mathrm{mL}$ blood was measured in a gamma counter (Perkin Elmer Packard, Cobra II). One milliliter of the $5 \mathrm{~min}, 30 \mathrm{~min}, 1 \mathrm{~h}$ and $4 \mathrm{~h}$ blood samples was centrifuged and $200 \mu \mathrm{L}$ plasma was removed, treated with $400 \mu \mathrm{L}$ ethanol and centrifuged to remove plasma proteins. The supernatant was analyzed for metabolites by RP-HPLC. In patients 2 and 3, urine was collected up to $18 \mathrm{~h}$ p.i.. Radioactivity concentration was measured for a $1 \mathrm{~mL}$ sample and total excreted activity was calculated. Due to logistical reasons, no urinary samples were obtained for patients 1 and 4 . In patient $2,10 \mathrm{~mL}$ of a urine sample obtained at $2 \mathrm{~h}$ was loaded on a C18 column and eluted with $1 \mathrm{~mL}$ of ethanol and analyzed by RP-HPLC.

Table I. Patient Characteristics. I Measured on TRUS.

\begin{tabular}{|c|c|c|c|c|c|c|c|c|}
\hline Patient & Age & $\begin{array}{l}\text { Weight } \\
(\mathrm{kg}) / \\
\text { height }(\mathrm{m})\end{array}$ & $\begin{array}{l}\text { Result core needle biopsy: } \\
\text { Gleason score, TNM classifica- } \\
\text { tion, tumor site and extension }\end{array}$ & $\begin{array}{l}\text { PSA } \\
(\mathrm{ng} / \mathrm{mL})\end{array}$ & $\begin{array}{l}\text { Prostate } \\
\text { volume } \\
(\mathrm{mL})^{1}\end{array}$ & $\begin{array}{l}\text { TRUS } \\
\text { (Transrectal } \\
\text { Ultrasound) }\end{array}$ & $\begin{array}{l}\text { DRE (Digital } \\
\text { Rectal } \\
\text { Examination) }\end{array}$ & Therapy \\
\hline 1 & 64 & $103 / 1.86$ & $\begin{array}{l}4 / 6 \text { biopsies positive in left lobe } \\
\text { [Gleason } 6(3+3), T 1 c], \text { right lobe } \\
\text { negative, tumor fraction } 2 \%\end{array}$ & 10.0 & 20 & No abnormalities & $\begin{array}{l}\text { No } \\
\text { abnormalities }\end{array}$ & $\begin{array}{l}\text { 125I seed } \\
\text { implantation }\end{array}$ \\
\hline 2 & 77 & $100 / 1.83$ & $\begin{array}{l}3 / 4 \text { biopsies positive in right } \\
\text { lobe [Gleason } 7(4+3) \text {, T2a], left } \\
\text { lobe negative, tumor fraction up } \\
\text { to } 40 \%\end{array}$ & 4.6 & 40 & $\begin{array}{l}\text { Suspicious lesion } \\
\text { in right prostatic } \\
\text { lobe }\end{array}$ & $\begin{array}{l}\text { Enlargement of } \\
\text { both prostatic } \\
\text { lobes }\end{array}$ & $\begin{array}{l}\text { Percutaneous ra- } \\
\text { diotherapy and } \\
\text { androgen depriva- } \\
\text { tion therapy }\end{array}$ \\
\hline 3 & 70 & $78 / 1.78$ & $\begin{array}{l}\text { Biopsies positive in right lobe } \\
\text { [Gleason } 7(4+3), T 2 b], \text { left lobe } \\
\text { negative, tumor fraction } 10 \%\end{array}$ & 9.9 & 35 & $\begin{array}{l}\text { Suspicious lesion } \\
\text { in right prostatic } \\
\text { lobe }\end{array}$ & $\begin{array}{l}\text { Enlargement of } \\
\text { right prostatic } \\
\text { lobe with solid } \\
\text { nodule }\end{array}$ & $\begin{array}{l}\text { Percutaneous ra- } \\
\text { diotherapy and } \\
\text { interstitial } \\
\text { after-loading }\end{array}$ \\
\hline 4 & 73 & $71.5 / 1.70$ & $\begin{array}{l}\text { Biopsies positive in both sides of } \\
\text { the prostatic gland [Gleason } 7 \\
(4+3), \text { T2b], tumor fraction }> \\
90 \% \text { in left lobe, } \\
<1 \% \text { in right lobe }\end{array}$ & 26.2 & 70 & $\begin{array}{l}\text { Considerable } \\
\text { enlargement of } \\
\text { both prostatic } \\
\text { lobes, very inho- } \\
\text { mogeneous tex- } \\
\text { ture bilaterally }\end{array}$ & $\begin{array}{l}\text { Enlargement of } \\
\text { both prostatic } \\
\text { lobes, suspi- } \\
\text { cious solid nod- } \\
\text { ules bilaterally }\end{array}$ & $\begin{array}{l}\text { Prostatectomy and } \\
\text { local lymph node } \\
\text { dissection }\end{array}$ \\
\hline
\end{tabular}




\section{Data analysis}

The uptake of ${ }^{64} \mathrm{Cu}$-CB-TE2A-AR06 was quantified by standardized uptake values (SUVs) normalized to the patient's body weight. Tumors were visually delineated in the slice with the highest tracer uptake and the maximum SUVs were recorded. Because of the small tumor size, no $\mathrm{SUV}_{\text {mean }}$ values were determined because they would have been heavily influenced by partial volume effects. For normal organs, circular regions of interest were placed in the center of the organ to minimize partial volume effects. Results are presented as mean \pm one standard deviation. Because of the small sample size, no further statistical analysis was performed.

Using the image-derived time activity curves and the amount of activity excreted in the urine, absorbed doses were calculated with OLINDA/EXM 1.0 using the dynamic bladder model with a 3-hour voiding interval (Vanderbilt University, Nashville, $\mathrm{TN})$.

\section{Results}

The mean and standard deviation of the administered mass of ${ }^{64} \mathrm{Cu}$-CB-TE2A-AR06 was $14 \pm 4 \mu \mathrm{g}$ (range 10-17 $\mu \mathrm{g}$ ). The mean administered activity was
$184 \pm 51 \mathrm{MBq}$ (range 130-233 MBq). There were no adverse or clinically detectable pharmacologic effects in any of the 4 subjects. No significant changes in vital signs or the results of laboratory studies or electrocardiograms were observed.

In 3 out of 4 patients, the prostate tumor was visualized with high contrast on the ${ }^{64} \mathrm{Cu}-\mathrm{CB}-\mathrm{TE} 2 \mathrm{~A}-\mathrm{AR} 06$ PET scans at all time points (Figure 2 and 3 ). In patient 1 (less than 5\% tumor cells in the biopsy samples), modest focal uptake was observed. The location of focal tracer uptake corresponded well to the location of the tumor as determined by preoperative biopsies. In the patient who underwent surgery after the PET/CT scan, GRPr autoradiography confirmed the presence of GRP receptors in the tumor tissue (Figure 3). ${ }^{64} \mathrm{Cu}-\mathrm{CB}-\mathrm{TE} 2 \mathrm{~A}-\mathrm{AR} 06$ was rapidly cleared from the blood and excreted by the kidneys (Figure 4A). In patients 2 and $3,80 \%$ and $70 \%$ of the injected activity were found in the urine within $18 \mathrm{~h}$ p.i.. Only the parent compound was detected in the $2 \mathrm{~h}$ urine sample. No metabolites were detected in the plasma at 5 min p.i.. At the later time points, the activity concentration in the plasma samples was below the threshold for HPLC analysis.

A

B

C

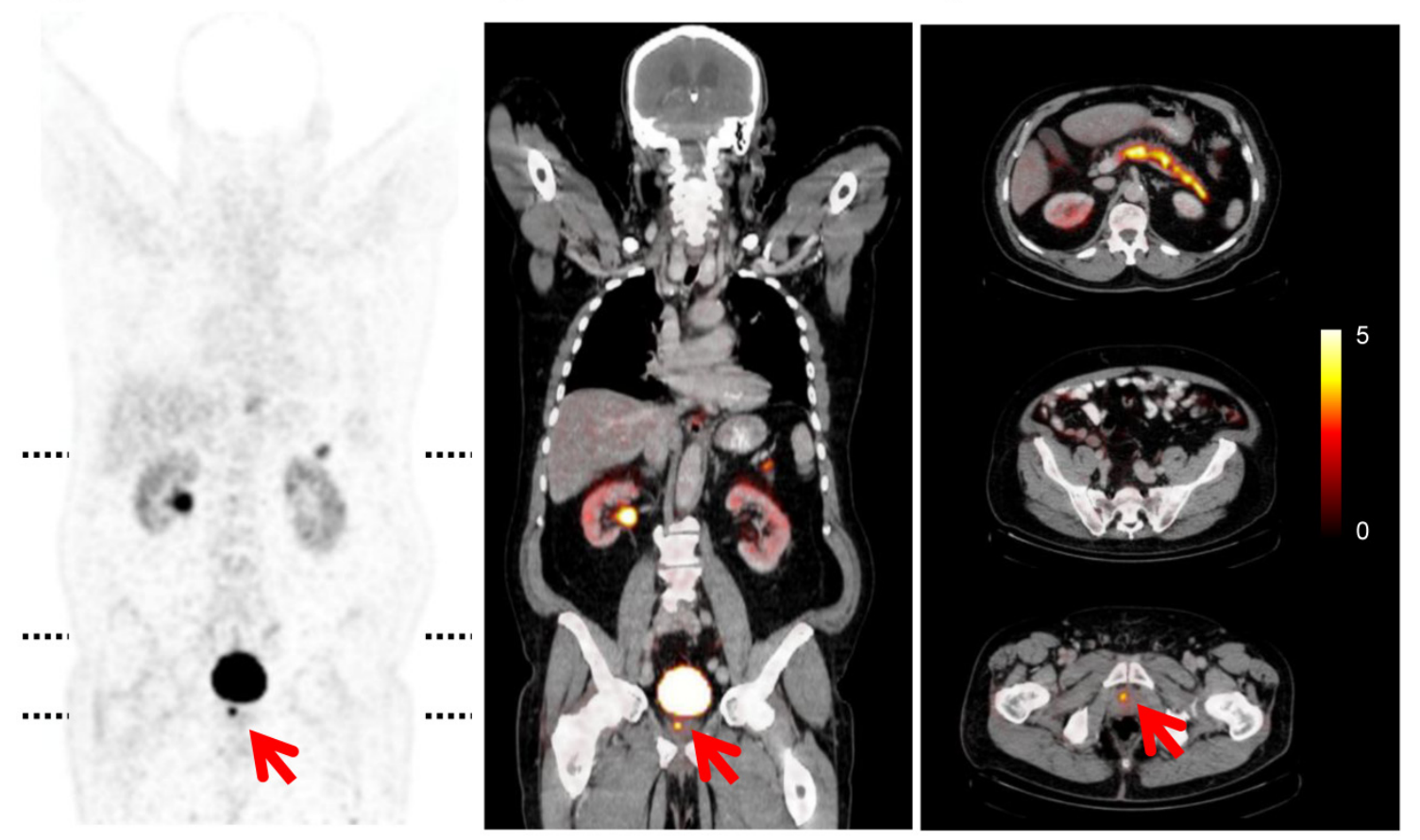

Figure 2. ${ }^{64} \mathrm{Cu}-\mathrm{CB}-\mathrm{TE} 2 \mathrm{~A}-\mathrm{AR} 06 \mathrm{PET} / \mathrm{CT}$ study of patient 2. Images were acquired $4 \mathrm{~h}$ p.i.. A, B: Coronal sections of PET and fused PET/CT. C: Axial PET/CT fusion images at the levels indicated by dotted lines in $\mathrm{A}$. There is intense uptake by the prostate tumor (red arrows) and the pancreas. Kidneys, liver and intestines show only low tracer uptake. The PET images are scaled to an SUV of 5 (color bar). 

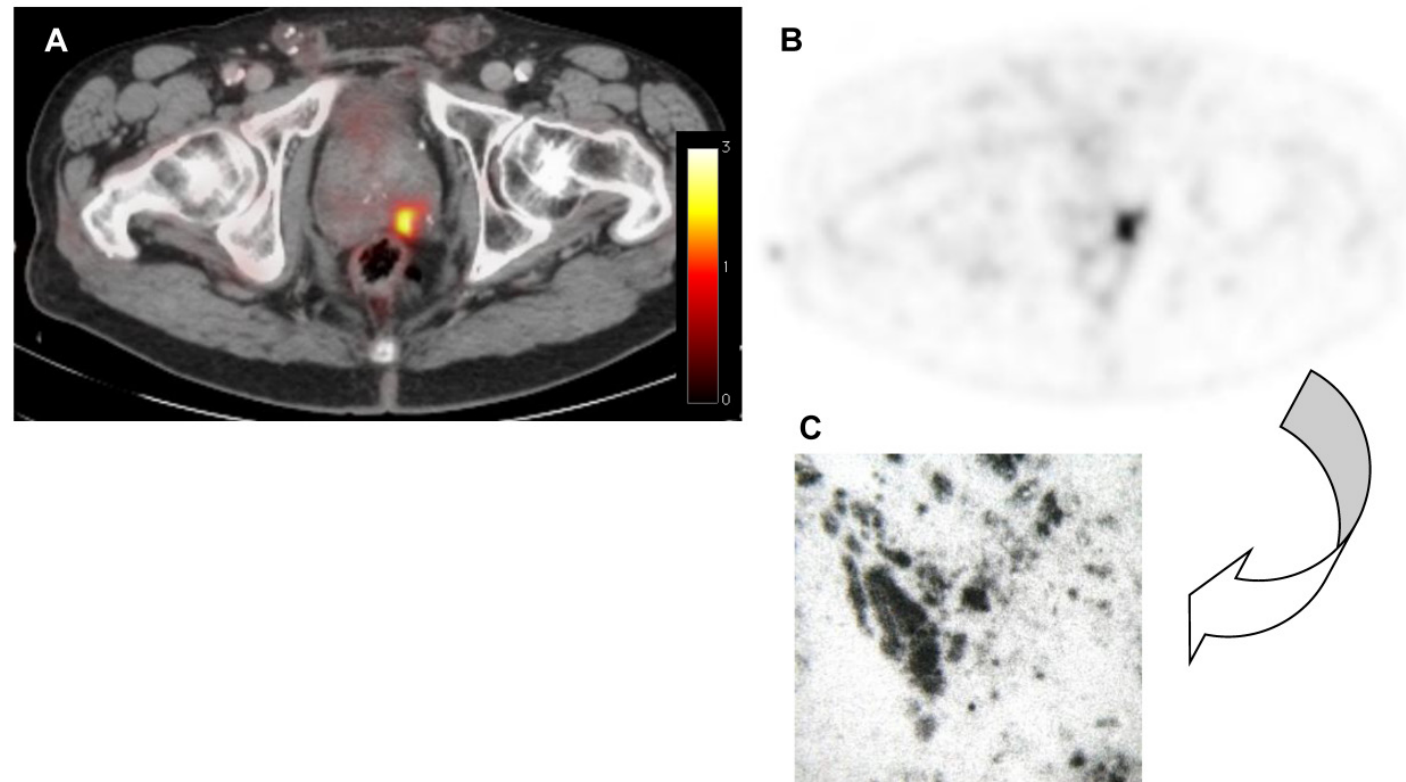

Figure 3. Correlation between in vivo PET and ex vivo autoradiography. A, B: Transaxial fused PET/CT and PET 4 h p.i.. C: Ex vivo GRP receptor autoradiography demonstrating GRPr expression by the tumor.

A

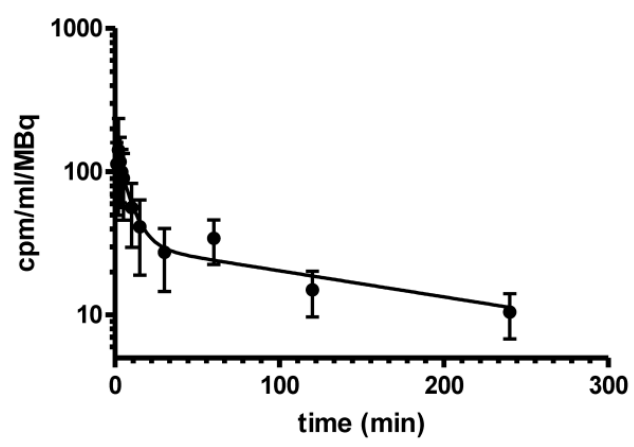

B

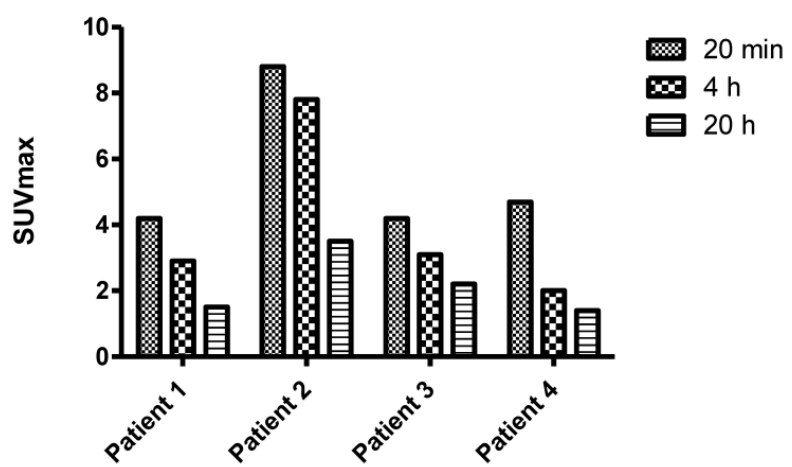

Figure 4. A: Radioactivity concentration in the blood over time (mean and standard deviation) and bi-exponential fit of the data. The initial half-life of ${ }^{64} \mathrm{Cu}-\mathrm{CB}-\mathrm{TE} 2 \mathrm{~A}-\mathrm{AR} 06$ is 5 minutes and the terminal half-life 165 minutes. B: Radioactivity concentration in the tumors over time.

Radioactivity uptake above background was seen in kidneys, bladder, pancreas and intestine (Figures 2 and 3). At $4 \mathrm{~h}$ p.i., average $S \mathrm{SV}_{\text {mean }}$ was $1.64 \pm$ 0.37 (kidney parenchyma), $5.86 \pm 5.34$ (urinary tract collection system), $14.03 \pm 6.63$ (bladder), and $6.73 \pm$ 3.34 (pancreas). Activity further cleared from these organs until the latest acquisition time point at $20 \mathrm{~h}$ p.i. $\left[\mathrm{SUV}_{\text {mean }} 0.71 \pm 0.34\right.$ (kidney parenchyma) and 0.28 \pm 0.22 (pancreas)]. Liver, intestine and prostate showed low uptake at all-time points $\left(\mathrm{SUV}_{\text {mean }} 1.8 \pm\right.$ $1.02,0.78 \pm 0.68$ and $0.95 \pm 0.42$ after $4 \mathrm{~h}$ ). Washout of radioactivity was slower for tumors than for normal organs (Figure 4B), resulting in steadily increasing tumor-to-organ ratios over time (Figure 5).

An effective radiation dose of $0.019 \pm 0.008$ $\mathrm{mSv} / \mathrm{MBq}$ was calculated. This resulted in an effective dose per study ranging from 2.47 to $4.49 \mathrm{mSv}$. The highest absorbed dose was found in the urinary bladder wall $(0.176 \pm 0.001 \mathrm{mSv} / \mathrm{MBq})$ and the pancreas $(0.094 \pm 0.027 \mathrm{mSv} / \mathrm{MBq})$. Individual organ doses are shown in Table 2 in comparison to literature data for ${ }^{18} \mathrm{~F}$-fluorocholine (11).

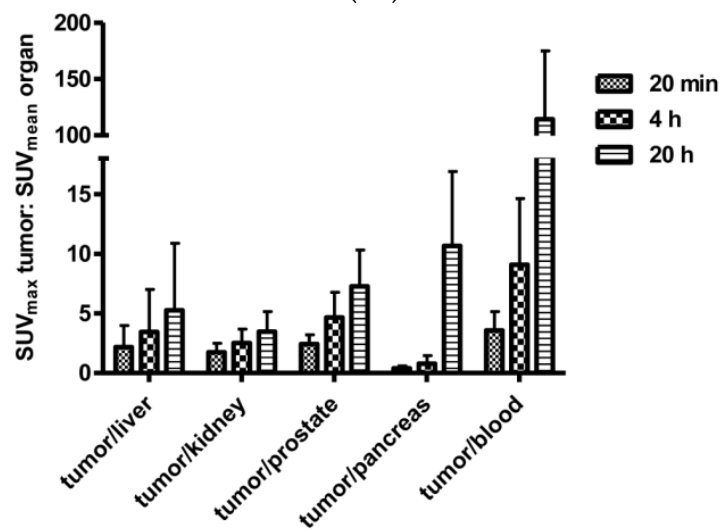

Figure 5. Tumor-to-normal-organ ratios over time. 
Table 2. Radiation doses ( $\mathrm{mSv} / \mathrm{MBq}$ ) after administration of ${ }^{64} \mathrm{Cu}-\mathrm{CB}-\mathrm{TE2} A-\mathrm{AR} 06$ in comparison to literature data on $18 \mathrm{~F}$-fluorocholine $(I I)$.

\begin{tabular}{lll}
\hline Organ & ${ }^{64} \mathrm{Cu}-\mathrm{CB}-\mathrm{TE} 2 \mathrm{~A}-\mathrm{AR} 06$ & ${ }^{18} \mathrm{~F}$-fluorocholine \\
\hline Liver & $0.039 \pm 0.020$ & $0.059 \pm 0,012$ \\
Spleen & $0.031 \pm 0.024$ & $0.054 \pm 0,021$ \\
Pancreas & $0.094 \pm 0.027$ & not determined \\
Kidney & $0.033 \pm 0.008$ & $0.159 \pm 0,072$ \\
Urinary bladder wall & $0.176 \pm 0.001$ & $0.063 \pm 0,060$ \\
Effective dose & $0.019 \pm 0.008$ & $0.031 \pm 0,007$ \\
\hline
\end{tabular}

\section{Discussion}

This pilot clinical study confirms the favorable biodistribution and high tumor uptake of GRPr antagonists that have been observed in several preclinical studies (8). The GRPr antagonist ${ }^{64} \mathrm{Cu}-\mathrm{CB}-\mathrm{TE} 2 \mathrm{~A}-\mathrm{AR} 06$ rapidly cleared from organs with physiologic GRPr expression and was retained significantly longer in human prostate cancers. This resulted in steadily increasing tumor-to-background ratios over time. Due to the rapid renal clearance of ${ }^{64} \mathrm{Cu}-\mathrm{CB}-\mathrm{TE} 2 \mathrm{~A}-\mathrm{AR} 06$, the calculated radiation exposure for patients was comparable to a scan with the PET imaging probe ${ }^{18} \mathrm{~F}$-fluorocholine (11).

Several other probes are in clinical development for imaging of prostate cancer based on altered metabolism, enzyme and receptor expression (12). The amino acid analogue anti-18F-FACBC (anti-1-amino-3-18 F-fluorocyclobutane-1-carboxylic acid) is accumulated by prostate cancer cells via various amino acid transporters, especially the ASC (alanine-serine-cysteine) transporter (12). Anti-18F-FACBC has shown encouraging results for imaging of primary prostate cancer, as well as lymph node metastases of prostate cancer (13). A recent pilot study has compared anti-18F-FACBC and ${ }^{11} \mathrm{C}$-choline in patients with biochemical recurrence of prostate cancer and found a higher detection rate with anti-18F-FACBC than with ${ }^{11} \mathrm{C}$-choline (14).

The enzyme prostate specific membrane antigen (PSMA, also known as folate hydrolase I and carboxypeptidase II) is expressed at the cell membrane of normal prostate cells, but is significantly up-regulated in prostate cancer (12). PSMA expression of prostate cancer has been targeted with antibodies and small molecule inhibitors of PSMA enzymatic activity (12). The radiolabeled antibody ${ }^{111} \mathrm{In}$-capromab has shown limited sensitivity for detection of prostate cancer, probably because it targets the intracellular portion of PSMA, which is not readily accessible by the antibody (12). Markedly higher uptake has been observed for the radiolabeled antibody J591, which targets the extracellular portion of PSMA. In pilot studies, high uptake of ${ }^{89} \mathrm{Zr}-\mathrm{DFO}-\mathrm{J} 591$ was observed in primary prostate cancer (15), as well as in advanced castration resistant prostate cancer (16). While these data clearly indicate that PSMA is an interesting target for prostate cancer imaging, a disadvantage of ${ }^{89} \mathrm{Zr}$-DFO-J591 is its slow tumor uptake and slow blood clearance, which result in a high radiation exposure to the patient, and require imaging several days post injection. In contrast to antibody-based approaches for PSMA imaging, radiolabeled small molecule PSMA inhibitors demonstrate a fast blood clearance and rapid tumor uptake. Imaging can be performed within one hour post injection. Both ${ }^{18} \mathrm{~F}$ - and ${ }^{68} \mathrm{Ga}$-labeled PSMA inhibitors have shown intense uptake in prostate cancer metastases $(17,18)$. A recent study has compared PET/CT with the ${ }^{68} \mathrm{Ga}$-labeled PSMA inhibitor Glu-NH-CO-NH-Lys-(Ahx)-[ $\left.{ }^{68} \mathrm{Ga}(\mathrm{HBED}-\mathrm{CC})\right]$ and ${ }^{18} \mathrm{~F}$-fluoromethylcholine PET/CT in 37 patients with metastatic prostate cancer. More metastatic lesions were detected with Glu-NH-CO-NH-Lys-(Ahx)[ $\left.{ }^{68} \mathrm{Ga}(\mathrm{HBED}-\mathrm{CC})\right]$ and lesion-to-background ratios were higher than for ${ }^{18} \mathrm{~F}$-fluoromethylcholine (19).

${ }^{18} \mathrm{~F}$-fluoro-5a-dihydrotestosterone $\left({ }^{18} \mathrm{~F}-\mathrm{FDHT}\right)$ is a labeled androgen analog that evaluates androgen receptor expression in prostate cancer (20). However, serum testosterone needs to be at castration level for successful targeting of prostate cancer, which limits the usefulness of this tracer as a diagnostic agent (20).

Future studies will be necessary to compare the ability of these different agents to image primary and metastatic prostate cancer. Because of the marked heterogeneity of prostate cancer at the time of diagnosis (21), and even more so at the time of recurrence (22), it is likely that several image probes will prove clinically useful for imaging various types and stages of prostate cancer.

A large variety of bombesin receptor ligands have been tested preclinically (23-25), most of which were bombesin agonists. Among this large series of compounds, few were further evaluated in humans. An example is the $99 \mathrm{~m}$ Tc-labeled bombesin analogue 99mTc-RP527, which was tested in patients with breast and prostate cancers (26). A frequent limitation of GRPr-targeting ligands has been their high uptake in the gastrointestinal tract, which may limit the detection of metastatic prostate cancer. Motivated by the superior imaging characteristics of somatostatin receptor antagonists $(27)$, we $(8,9)$ and others $(28)$ have studied GRPr antagonists in preclinical models of prostate cancer. In these studies, the antagonist demonstrated higher tumor uptake and lower gastrointestinal uptake than the agonists. Remarkably, normal tissues expressing GRPr, such as mouse or rat pancreas, consistently demonstrated much faster washout of the radioactivity than prostate cancers $(8$, 9, 28). 
In a very recent publication, a ${ }^{68} \mathrm{Ga}$-labeled GRPr antagonist (BAY86-7548, RM2) (29) was evaluated in patients with primary and recurrent prostate cancer. This radiotracer demonstrated focal uptake in primary prostate cancer, as well as lymph node metastases. In one patient, bone metastases were false negative on BAY86-7548 PET/CT. Because of the short half-life of ${ }^{68} \mathrm{Ga}$, the kinetics of BAY86-7548 could only be studied over a period of approximately $2 \mathrm{~h}$, whereas we studied tumor uptake and biodistribution of ${ }^{64} \mathrm{Cu}-\mathrm{CB}-\mathrm{TE} 2 \mathrm{~A}-\mathrm{AR} 06$ over a period of $20 \mathrm{~h}$. Information about the retention of GRPr antagonists is important for estimating patient dose and for potential therapeutic applications. Furthermore, the increasing contrast between tumor and normal organs over time (Figure 5) suggests that delayed imaging may be beneficial for detection and staging of prostate cancer with GRPr antagonists.

In our patient population, the kinetics of the GRPr antagonist ${ }^{64} \mathrm{Cu}-\mathrm{CB}-\mathrm{TE} 2 \mathrm{~A}-\mathrm{AR} 06$ were similar to preclinical studies. ${ }^{64} \mathrm{Cu}-\mathrm{CB}-\mathrm{TE} 2 \mathrm{~A}-\mathrm{AR} 06$ was rapidly accumulated by prostate cancer and cleared much slower from the tumors than from normal organs. The mechanisms for these differences between normal tissues and prostate cancer tissue are currently not known. However, our clinical data clearly indicate that this phenomenon is not limited to mouse models of prostate cancer, but occurs in a similar way in patients.

The high tumor uptake of GRPr ligands make radionuclide therapy with GRPr ligands labeled with beta (30) or alpha (31) emitters feasible. The low intestinal and kidney uptake of GRPr antagonists, as well as the rapid washout of activity from the pancreas, observed in the present study and preclinically $(8,9)$, make these compounds particularly attractive for peptide receptor targeted radiotherapy (PRRT). Thus, imaging and therapeutic peptides could potentially be used as theranostics for prostate cancer.

Moreover, GRPrs have been demonstrated to be overexpressed in various other malignancies, such as small cell lung cancer, breast cancer and intratumoral blood vessels of ovarian malignancies $(32,33)$. Thus, PET/CT with ${ }^{64} \mathrm{Cu}-\mathrm{CB}-\mathrm{TE} 2 \mathrm{~A}-\mathrm{AR} 06$ may not only be used in prostate cancer, but also in several other prevalent malignant tumors.

\section{Conclusion}

These preliminary patient data are consistent with previous preclinical studies and suggest a favorable tumor uptake and image contrast of GRPr ligands for prostate cancer imaging. Studies in a considerably larger number of patients will be necessary in order to determine the sensitivity of ${ }^{64} \mathrm{Cu}-\mathrm{CB}-\mathrm{TE} 2 \mathrm{~A}-\mathrm{AR} 06 \mathrm{PET} / \mathrm{CT}$ in relation to tumor size and other factors, such as Gleason scores. Nevertheless, the encouraging preliminary data of this study indicate that further clinical evaluation of ${ }^{64} \mathrm{Cu}-\mathrm{CB}-\mathrm{TE} 2 \mathrm{~A}-\mathrm{AR} 06$ and other GRPr antagonists is warranted.

\section{Acknowledgements}

This work was supported in part by the German Academic Exchange Service and the German Cancer Consortium (DKTK).

The authors thank Franklin Torres for his helpful comments on the manuscript.

\section{Competing Interests}

The authors have declared that no competing interest exists.

\section{References}

1. Hricak H, Choyke PL, Eberhardt SC, Leibel SA, Scardino PT. Imaging prostate cancer: a multidisciplinary perspective. Radiology. 2007;243:28-53.

2. Picchio M, Briganti A, Fanti S, et al. The role of choline positron emission tomography/computed tomography in the management of patients with prostate-specific antigen progression after radical treatment of prostate cancer. Eur Urol. 2011;59:51-60.

3. Souvatzoglou M, Weirich $G$, Schwarzenboeck S, et al. The sensitivity of [11C]choline PET/CT to localize prostate cancer depends on the tumor configuration. Clin Cancer Res. 2011;17:3751-3759.

4. Jensen RT, Battey JF, Spindel ER, Benya RV. International Union of Pharmacology. LXVIII. Mammalian bombesin receptors: nomenclature, distribution, pharmacology, signaling, and functions in normal and disease states. Pharmacol Rev. 2008;60:1-42.

5. Markwalder R, Reubi JC. Gastrin-releasing peptide receptors in the human prostate: relation to neoplastic transformation. Cancer Res. 1999;59:1152-1159.

6. Bodei L, Ferrari M, Nunn A, et al. 177Lu-AMBA Bombesin analogue in hormone refractory prostate cancer patients: a phase I escalation study with single-cycle administrations [abstract]. Eur J Nucl Med Mol Imaging. 2007;34 (Suppl 2):S221.

7. Schwartsmann G, DiLeone LP, Horowitz M, et al. A phase I trial of the bombesin/gastrin-releasing peptide (BN/GRP) antagonist RC3095 in patients with advanced solid malignancies. Invest New Drugs. 2006;24:403-412.

8. Abiraj K, Mansi R, Tamma ML, et al. Bombesin antagonist-based radioligands for translational nuclear imaging of gastrin-releasing Peptide receptor-positive tumors. J Nucl Med. 2011;52:1970-1978.

9. Mansi R, Wang X, Forrer $\mathrm{F}$, et al. Evaluation of 1,4,7,10-tetraazacyclododecane-1,4,7,10-tetraacetic acid-conjugated bombesin-based radioantagonist for the labeling with single-photon emission computed tomography, positron emission tomography, and therapeutic radionuclides. Clin Cancer Res. 2009;15:5240-5249.

10. Shokeen M, Anderson C. Molecular Imaging of Cancer with Copper-64 Radiopharmaceuticals and Positron Emission Tomography (PET). Accounts of Chemical Research. 2009;42:832-841.

11. DeGrado TR, Reiman RE, Price DT, Wang S, Coleman RE. Pharmacokinetics and radiation dosimetry of 18F-fluorocholine. J Nucl Med. 2002;43:92-96.

12. Jadvar H. Molecular Imaging of Prostate Cancer with PET. J Nucl Med. 2013;54:1685-1688.

13. Schuster DM, Votaw JR, Nieh PT, et al. Initial experience with the radiotracer anti-1-amino-3-18F-fluorocyclobutane-1-carboxylic acid with PET/CT in prostate carcinoma. J Nucl Med. 2007;48:56-63.

14. Nanni C, Schiavina R, Boschi S, et al. Comparison of 18F-FACBC and 11C-choline PET/CT in patients with radically treated prostate cancer and biochemical relapse: preliminary results. Eur J Nucl Med Mol Imaging. 2013;40 Suppl 1:S11-17.

15. Osborne JR, Green DA, Spratt DE, et al. A Prospective Pilot Study of 89Zr-J591/PSMA Positron Emission Tomography (PET) in Men with Localized Prostate Cancer Undergoing Radical Prostatectomy. J Urol. 2013; [epub ahead of print]

16. Morris M, Pandit-Taskar N, Carrasquillo J, et al. Phase I trial of zirconium 89 (Zr89) radiolabeled J591 in metastatic castration-resistant prostate cancer (mCRPC). J Clin Oncol. 2013;31 (suppl 6).

17. Afshar-Oromieh A, Malcher A, Eder M, et al. PET imaging with a [68Ga]gallium-labelled PSMA ligand for the diagnosis of prostate cancer: biodistribution in humans and first evaluation of tumour lesions. Eur J Nucl Med Mol Imaging. 2013;40:486-495.

18. Cho SY, Gage KL, Mease RC, et al. Biodistribution, tumor detection, and radiation dosimetry of 18F-DCFBC, a low-molecular-weight inhibitor of 
prostate-specific membrane antigen, in patients with metastatic prostate cancer. J Nucl Med. 2012;53:1883-1891.

19. Afshar-Oromieh A, Zechmann CM, Malcher A, et al. Comparison of PET imaging with a Ga-labelled PSMA ligand and F-choline-based PET/CT for the diagnosis of recurrent prostate cancer. Eur J Nucl Med Mol Imaging. 2013.

20. Larson SM, Morris M, Gunther I, et al. Tumor localization of 16beta-18F-fluoro-5alpha-dihydrotestosterone versus 18F-FDG in patients with progressive, metastatic prostate cancer. J Nucl Med. 2004;45:366-373.

21. Schrecengost R, Knudsen KE. Molecular pathogenesis and progression of prostate cancer. Semin Oncol. 2013;40:244-258.

22. Scher HI, Morris MJ, Larson S, Heller G. Validation and clinical utility of prostate cancer biomarkers. Nat Rev Clin Oncol. 2013;10:225-234.

23. Craft JM, De Silva RA, Lears KA, et al. In vitro and in vivo evaluation of a 64Cu-labeled NOTA-Bn-SCN-Aoc-bombesin analogue in gastrin-releasing peptide receptor expressing prostate cancer. Nucl Med Biol. 2012;39:609-616.

24. Chen X, Park R, Hou Y, et al. microPET and autoradiographic imaging of GRP receptor expression with 64Cu-DOTA-[Lys3]bombesin in human prostate adenocarcinoma xenografts. J Nucl Med. 2004;45:1390-1397.

25. Prasanphanich AF, Nanda PK, Rold TL, et al. [64Cu-NOTA-8-Aoc-BBN(7-14)NH2] targeting vector for positron-emission tomography imaging of gastrin-releasing peptide receptor-expressing tissues. Proc Natl Acad Sci U S A. 2007;104:12462-12467.

26. Van de Wiele C, Dumont F, Dierckx RA, et al. Biodistribution and dosimetry of $(99 \mathrm{~m}) \mathrm{Tc}-\mathrm{RP} 527$, a gastrin-releasing peptide (GRP) agonist for the visualization of GRP receptor-expressing malignancies. J Nucl Med. 2001;42:1722-1727.

27. Ginj M, Zhang H, Waser B, et al. Radiolabeled somatostatin receptor antagonists are preferable to agonists for in vivo peptide receptor targeting of tumors. Proc Natl Acad Sci U S A. 2006;103:16436-16441.

28. Schroeder RP, Muller C, Reneman S, et al. A standardised study to compare prostate cancer targeting efficacy of five radiolabelled bombesin analogues. Eur J Nucl Med Mol Imaging. 2010;37:1386-1396.

29. Kahkonen E, Jambor I, Kemppainen J, et al. In Vivo Imaging of Prostate Cancer Using [68Ga]-Labeled Bombesin Analog BAY86-7548. Clin Cancer Res. 2013;19:5434-5443.

30. Maddalena ME, Fox J, Chen J, et al. 177Lu-AMBA biodistribution, radiotherapeutic efficacy, imaging, and autoradiography in prostate cancer models with low GRP-R expression. J Nucl Med. 2009;50:2017-2024.

31. Wild D, Frischknecht $M$, Zhang $H$, et al. Alpha- versus beta-particle radiopeptide therapy in a human prostate cancer model (213Bi-DOTA-PESIN and 213Bi-AMBA versus 177Lu-DOTA-PESIN). Cancer Res. 2011;71:1009-1018.

32. Reubi JC, Wenger S, Schmuckli-Maurer J, Schaer JC, Gugger M. Bombesin receptor subtypes in human cancers: detection with the universal radioligand (125)I-[D-TYR(6), beta-ALA(11), PHE(13), NLE(14)] bombesin(6-14). Clin Cancer Res. 2002;8:1139-1146.

33. Fleischmann A, Waser B, Reubi JC. Overexpression of gastrin-releasing peptide receptors in tumor-associated blood vessels of human ovarian neoplasms. Cell Oncol. 2007;29:421-433. 